\title{
Visual discrimination learning and memory in nocturnal prosimians
}

\author{
ANNETTE EHRLICH and ALAN D. MUSICANT \\ California State University, Los Angeles, California 90032
}

\begin{abstract}
The ability of two nocturnal prosimians-greater galago and slow loris-to learn and to remember two-dimensional black-white pattern discriminations was investigated. There was no significant species difference. Both were found to be: sensitive to the number of visual cues available, able to benefit from repeated exposure to similar problems, capable of retaining previously learned material over a long period of time. Although they are individually quite variable in performance, these primitive primates are by no means untrainable on visual discrimination problems, as previous reports have suggested.
\end{abstract}

The learning abilities of primates belonging to the suborder Prosimae have not been investigated extensively. As Hodos (1970; Hodos \& Campbell, 1969) and also Masterton and Skeen (1972) have pointed out, this is unfortunate because they are a particularly interesting group of animals, one to which more attention should be devoted. The rationale offered by these authors is the following: The earliest or stem primates were prosimians; it is from this group that anthropoids (monkeys, apes, and humans) descended. Prosimians are known to have changed less in the course of their long evolutionary history than have the more recently evolved anthropoids. Thus, although they are different from earlier forms, living prosimians nevertheless offer a unique opportunity to understand what our original primate ancestors were like.

Of the many prosimian species, most are nocturnal, and it is this subgroup that seems to have retained the greatest proportion of primitive primate characteristics (Charles-Dominique \& Martin, 1972). Two such species, the greater galago and the slow loris, were selected for study here. They come from different continents (Africa and Asia, respectively), but they resemble each other closely in terms of brain morphology, size, diet, and habitat.

The particular task chosen was two-dimensional pattern discrimination. This would not seem, on an a priori basis, to be an ideal test situation to employ with nocturnal animals. However, several factors guided its choice. First, it is a task that has been used successfully with a wide range of vertebrates, and much comparison data is available (see Warren, 1965a, b, 1973, for reviews). Second, there is some

This research was supported by NIMH Grants 19196 and 15896 to the senior author and by a grant from the Associated Students of California State University at Los Angeles to the junior author. The assistance of Penny Jarecke in the collection and analysis of data is gratefully acknowledged. reason to believe that vision is an important modality in prosimians. All forms, whether nocturnal or diurnal, possess a well-developed visual system with thalamic and cortical areas that are as extensive and as complexly layered as those of other primates (Hassler, 1966). Data from naturalistic studies (Doyle, 1974; Ehrlich, Brody, Race, \& Mendoza, Note 1) support the anatomical findings. In all forms, social interactions, e.g., dominance, grooming, play, etc., are initiated on a visual basis. In the nocturnal species, which are the only ones that hunt live prey, detection and capture are done visually. In fact, these nocturnal prosimians become inactive in total darkness. In these respects, prosimians differ from other nocturnal mammals, including their own evolutionary forbears-the insectivores (Eisenberg \& Gould, 1966). However, what remains unclear is the extent to which the prosimians can be trained, in a formal laboratory situation, to respond to small differences between visual stimuli. Previous reports on this topic are conflicting and, for a variety of reasons, unsatisfying. That fact provided a third reason for studying visual discrimination learning.

Both Andrew (1962) and Jolly (1964b) reported little or no success in training members of eight different prosimian species to make such discriminations. However, Andrew did not publish the actual test data and Jolly admitted that her animals never became properly acclimated to the test situation. "When removed from the home cage, lemurs grew hysterical, lorisoids sulked, and both refused to work" (1964a). As for the positive reports, several (Glickman, Clayton, Schiff, Guritz, \& Messe, 1965; Rumbaugh \& Arnold, 1971; Stevens, 1965) deal only with diurnal Madagascan lemurs, a group that is not typical of prosimians as a whole (Charles-Dominique \& Martin, 1972). The few (Ehrlich \& Calvin, 1967; Ordy \& Samorajski, 1968) that deal with nocturnal forms are limited by the fact that, as in the lemur studies, few subjects and/or test problems were em- 
ployed. These factors may account for why these reports have received so little attention. The prevailing view among reviewers (Buettner-Janusch, 1963; Doyle, 1974; Warren, 1965b, 1973; Zimmerman \& Torrey, 1965), based on the work of Andrew and of Jolly, is that, in contrast to the vast majority of vertebrates, prosimians are virtually untrainable on visual discrimination problems. In the present study, this issue was reexamined, along with some others not previously explored, i.e., the responsiveness of prosimians to variations in the number of visual cues available, the extent to which they can improve with practice on sets of similar problems, their ability to retain learned material over a long period of time, and the degree of variability both within and between closely related species.

\section{PART 1: ACQUISITION}

\section{Method}

Subjects. The subjects were eight slow lorises (Nycticebus coucang), five females and three males, and seven greater galagos (Galago crassicaudatus), three females and four males. All were adults; they were housed individually in a temperaturecontrolled room and were maintained on a reversed light cycle; testing was carried out during the dark part of the cycle. Diet consisted of Purina Monkey Chow plus fruit, mealworms, milk, and cottage cheese.

Apparatus. Research with other primates has shown that learning is most efficient if the stimuli to be discriminated are small and close together and the animal's response involves actually touching the correct stimulus (Horel, Schuck, \& Meyer, 1961; Schuck, 1960; Schuck, Polidora, McConnell, \& Meyer, 1961). In the present experiment, this was accomplished in the following ways: (1) Stimuli to be discriminated were $2.5 \mathrm{~cm}$ in height; (2) they were rear-projected onto two Plexiglas panels, $3 \mathrm{~cm}$ in diameter and $6 \mathrm{~cm}$ apart (measured center to center); (3) the operant response involved touching the panel on which the correct stimulus appeared. One problem arose with these arrangements. Slow lorises could not be trained to press the panels with sufficient force to activate even the lightest microswitch available. It was necessary, therefore, to design a special system-one that was both touch sensitive and also compatible with rear projection. It consisted of a modified drinkometer circuit with fine mesh wire screens which did not distort the image in front of the Plexiglas panel (see Fobes, Ehrlich, \& Williams, 1971, for details).

Testing was carried out in a light-tight, sound-deadened primate test chamber, $26.5 \mathrm{~cm}$ deep $\times 30 \mathrm{~cm}$ wide $\times 29 \mathrm{~cm}$ high. Mounted on one wall were the two Plexiglas panels; they were $11.5 \mathrm{~cm}$ above the floor (measured to center screen). Below and centered between them was a food cup. Stimuli were displayed by means of two $35-\mathrm{mm}$ slide projectors, made to advance in synchrony. These were equipped with $500-\mathrm{W}$ bulbs and with shutters. The luminance at each window without slides was $63 \mathrm{fL}$.

Presentation of the stimuli and recording of responses was done automatically. On each trial, a Moduprint recorded trial number, whether the response was correct or incorrect, and the side on which the response was made.

Procedure. Stimuli to be discriminated were presented simultaneously. The subjects were 24 -h food-deprived and received 190-mg banana-flavored pellets as reinforcers for correct responses. Each response, whether correct or not, advanced the slide projectors and initiated an 8-sec intertrial delay, during which the shutters mounted in front of the projectors remained closed. Test sessions, conducted 5 days a week, lasted until the animal had made 150 responses or until $45 \mathrm{~min}$ had elapsed. All problems were learned to the criterion of $27 / 30$ consecutive correct responses within a single session. If an animal failed to reach criterion after 2,500 trials on any problem, it was dropped from the experiment. Because Andrew (1962) and Jolly $(1964 a, b)$ had reported that the major difficulty in training prosimians was their tendency to develop consistent position preferences, a deliberate attempt was made here to discourage their formation. Ordinarily, the position of the correct stimulus varied randomly from trial to trial, with the sole exception that it could not appear more than four times in a row on the same side. However, if the animal made eight successive choices on one side, the correct stimulus appeared on the other side continuously until the animal had made two successive responses on that side.

To familiarize the animal with the apparatus, one training problem, a light-dark discrimination, was given. Thereafter, three series of pattern discrimination problems were presented; in all cases, the stimuli were black forms presented against a white background. The first series (A) consisted of 24 problems in which stimuli differed in form; they differed therefore in luminance as well, offering the animals more than one cue for problem solution. The second series (B) consisted of 10 problems in which, with stimuli equated for luminance (the same forms were used but in different orientations), the discrimination had to be made on the basis of shape alone. The third series $(C)$ consisted of five problems; as in series $A$, stimuli differed in form and hence in luminance, but this time the differences were relatively small. On each of the 39 problems, one stimulus arbitrarily was designated by the experimenters as correct. Both the correct stimulus and the order of presentation of problems was the same for all subjects.

Data for each series were analyzed separately. For series $\mathbf{A}$ and $B$, trials-to-criterion data were examined by means of mixed analyses of variance on which one variable was species and the other or repeated-measures variable was problem blocks (four six-problem blocks in series $A$ and two five-problem blocks in series B). Trials-to-criterion data for series $\mathrm{C}$ were examined by means of a $t$ test. The frequency of occurrence and duration (number of consecutive trials before the animal switched) of two kinds of error also was tabulated. These were: position preference (defined as eight successive choices on one side) and stimulus preferences (defined as eight successive choices of the incorrect pattern).

\section{Results}

Because they failed to reach criterion on one of the early problems, two animals (one female loris and one male galago) were dropped from the experiment. The data reported here are for the remaining 13 animals, all of which completed the series. No species differences were found on any of the measures; data for the two species were therefore combined. Interaction effects also failed to reach an acceptable level of significance.

Trials to criterion. Table 1 shows a comparison of the mean performance per problem on each of the three series. $A$ and $C$ did not differ significantly from each other, but B obviously was much more diffi-

Table 1

Trials to Criterion

\begin{tabular}{lccr} 
& \multicolumn{3}{c}{ Series } \\
& A & B & C \\
\hline Mean per problem & 279 & 448 & 276 \\
Standard deviation & 100 & 211 & 323 \\
Fastest learner & 137 & 173 & 79 \\
Slowest learner & 454 & 785 & 748 \\
\hline
\end{tabular}


cult than either of the others. Animals took significantly more trials to learn individual problems on series $B(t=2.27, d f=12, p<.05$, for comparison with $\mathrm{A} ; \mathrm{t}=3.54, \mathrm{df}=12, \mathrm{p}<.01$, for comparison with $\mathrm{C}$ ); and, although repeated testing on similar problems resulted in significant improvement on series $A(F=24.07, \mathrm{df}=3 / 36, \mathrm{p}<.01)$, no such improvement occurred on $B$. Figure 1 shows the within-series improvement on $A$; note that the sharpest decline in trials to criterion occurred during the first 12 problems.

Errors. There was no significant change from one series to another in either the frequency or the duration of stimulus and position preferences. Position preferences occurred significantly more often. For all problems combined, mean frequency per problem was $\mathbf{2 . 2}$ for position and $\mathbf{0 . 4}$ for stimulus preferences $(\mathrm{t}=3.42$, df $=7, \mathrm{p}<.05)$. Position preferences also had a significantly greater duration than stimulus preferences. Mean duration per problem was 15.6 trials for position preferences and 8.0 trials for stimulus preferences $(t=4.75, \mathrm{df}=7, \mathrm{p}<.01)$.

Individual variability. A consistent finding on all series was that within-species variability for trials to criterion was very large. As shown in Table 1 , it took the slowest learner in each series anywhere from three to nine times as many trials to reach criterion as the fastest learner. Data for individual animals were examined to see whether differences in the frequency and/or duration of the two error types accounted for some of the variability in overall learning speed, but no differences were found between fast and slow learners. Analysis on a problem-by-problem basis revealed variability of another sort; even fast learners fluctuated from problem to problem. Thus, all animals had at least one problem on which acquisition was quite rapid- 50 trials or less-and all but the fastest learner had one or

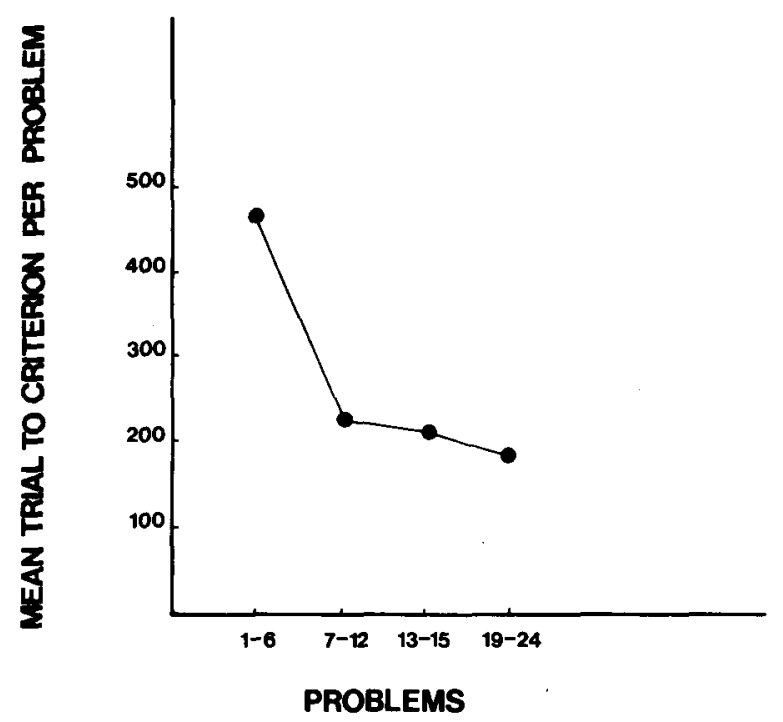

Figure 1. Within-series improvement on series $\mathbf{A}$. more problems on which acquisition was very slow900 trials or more. There did not seem to be anything special about the particular problems that caused difficulty; in fact, they varied from animal to animal. What was constant was the fact that, on problems that were readily learned, animals tended to start with a pronounced bias in favor of the correct stimulus. On discriminations that were acquired very slowly, initial biases for position or for the incorrect stimulus occurred, but they were not present in all cases. The distinguishing feature of performance on such problems was that learning was not gradual; animals remained at about the $50 \%$ correct level for hundreds of trials until, quite suddenly, they began to discriminate at a near perfect level and rapidly met criterion.

\section{PART II: RETENTION}

\section{Method}

The subjects were two slow lorises and two greater galagos. They were chosen from the original group of 13 because they had finished the last problem of series $C$ within 2 months of each other (20-22 months previously) and had not been used in any learning experiments in the interim. The mean of their acquisition scores in Part $I$ was close to the mean for the entire group $(949$ by comparison with 1,003). Apparatus and procedures were similar to those in Part I. Ten problems out of the original 39 were used. Three criteria were employed in their selection: (a) They represented varying degrees of difficulty (based on the mean number of trials to criterion for the group as a whole); the range for the 10 problems was 86 trials to 793 . (b) They were problems on which the standard deviation for acquisition by the group as a whole had been relatively low; the range was 62 to 539 (this criterion actually was difficult to meet because, when the mean number of trials to criterion was high, the standard deviation tended to be large). (c) The problems were obviously dissimilar from one another. The order in which these 10 problems were presented was the same for all four subjects, but it was not the same as during acquisition. This was done so as to randomize the presentation of easy and hard problems. Animals were retrained to the original criterion of $27 / 30$ consecutive correct responses in a single session. No attempt was made to discourage position preferences. The 27 trials necessary to meet criterion were subtracted from both the acquisition and retention scores; then the savings score for each animal was calculated as the difference between acquisition and retention divided by acquisition.

\section{Results}

On 9 of the 10 problems, retention was good. Mean savings scores on 6 of these were $91 \%-97 \%$; on 3 others, mean savings scores were $78 \%-79 \%$. Only one problem, the most difficult of the 10 (based on trials to criterion during acquisition) was poorly retained-mean savings $=48 \%$. For all problems, a significant relationship (at the .05 level or less) was demonstrated between the speed of the original learning and the speed of relearning. This was done by computing the correlation coefficient between the two sets of scores for each animal separately. These coefficients were: $.59, .68, .69, .87$. Stimulus errors were nonexistent. Although they were not punished by nonreinforcement, position errors had a shorter 
duration than during acquisition $(M=10, S D=2.1$ ). With respect to trials to criterion, the four subjects were considerably less yariable in their retention performance than they had been during the original learning $(F=33.78, \mathrm{df}=3 / 3, \mathrm{p}<.01)$; their ranking, relative to each other, however, was the same as it had been during acquisition.

\section{DISCUSSION}

Greater galagos and slow lorises have been shown to differ significantly from each other on some measures of naturally occurring behavior (e.g., Ehrlich, 1970, 1974) but, in the present case, on a laboratory task involving specific training, their performance was similar. Members of both species were able to learn two-dimensional visual discriminations; like other vertebrates tested on similar problems (see Warren, 1965a, b, 1973), they were found to be: (1) sensitive to the number of relevant cues available, learning faster when there were multiple cues rather than a single one; (2) able (at least on multiple-cue problems) to benefit from repeated exposure to similar problems; (3) capable of retaining previously learned material over a long period of time.

For the group as a whole, acquisition of visual discriminations proceeded at a relatively slow rate. However, there were large individual differences. The fact that some animals learned quite rapidly would seem to rule out the possibility that these species are simply inattentive to visual stimuli. On the contrary, the use of such stimuli with them would seem to be entirely appropriate. What remains to be explained is the degree of variability in performance that greater galagos and slow lorises exhibit, both among themselves and from problem to problem. A similar degree of variability, it should be noted, has been reported in a few other species-the domestic cat (Warren \& Baron, 1956), the squirrel monkey (Rumbaugh, 1968), the ringtail lemur (Stevens, 1965), and the cebus monkey (King \& Fobes, 1975) but, except for King and Fobes (1975), there has been little interest in seeking explanations.

In the present case, fluctuations in motivational level do not seem to provide an answer. Animals worked willingly at all times (they even learned to line themselves up at their cage doors in readiness for the day's testing) and ate all pellets they earned. A more likely explanation is that, like the cebus monkeys tested by King and Fobes (1975), slow and fast learners in the present study were pursuing different hypotheses. This is in accord with the fact that performance of slow learners often went quite suddenly from chance to near perfect. The fairly simple error analysis carried out here ruled out the possibility that differential tendencies to form stimulus and/or position preferences distinguished between slow and fast learners, but it was not possi- ble to explore systematically the strength of other possible sources of error. Levine (1965) has developed a precise mathematical technique for doing so, but his method was not applicable in the present instance, due to the relatively small number of problems employed and to the fact that, with position preferences being systematically discouraged, not all errors had an equal likelihood of occurring. However, it would be fruitful, in further research with these species, to utilize test situations, e.g., learning set, that yield data that are susceptible to such analysis.

That further research with these species is feasible has been shown here. Contrary to earlier reports by other authors (Andrew, 1962; Jolly, 1964b), nocturnal prosimians are by no means untrainable. There is, thus, no reason not to explore in greater depth the nature of their learning abilities and even to use them as suitable models for an exploration of the nature of individual differences in nonhuman primate learning.

\section{REFERENCE NOTE}

1. Ehrlich, A., Brody, I., Race, B., \& Mendoza, L. Preycatching in a nocturnal primate: The greater galago. Paper presented at Western Psychological Association meeting, 1975.

\section{REFERENCES}

ANDREw, R. J. Evolution of intelligence and vocal mimicking. Science, 1962, 137, 585-589.

BuetTNer-Janusch, J. An introduction to the primates. In J. Buettner-Janusch (Ed.), Evolutionary and genetic biology of primates (Vol. I). New York: Academic Press, 1963.

Charles-Dominique, P., \& Martin, R. D. Behaviour and ecology of nocturnal prosimians. In Advances in ethology. Supplement No. 9, Journal of Comparative Ethology. Berlin: Paul Parey, 1972.

DoYle, G. A. Behavior of prosimians. In A. M. Schrier, \& F. Stollnitz (Eds.), Behavior of nonhuman primates (Vol. V). New York: Academic Press, 1974.

EHRLICH, A. Response to novel objects in three lower primates: Greater galago, slow loris, and owl monkey. Behaviour, 1970, 37, 55-63.

EhRLICH, A. Infant development in two prosimian species: Greater galago and slow loris. Developmental Psychobiology, 1974, 7, 439-454.

Ehrlich, A., \& Calvin, W. Visual discrimination behavior in galago and owl monkey. Psychonomic Science, 1967, 9, 509-510.

EISENBERG, J. F., \& Gould, E. The behavior of Solenodon paradoxus in captivity with comments on the behavior of other insectivora. Zoologica, 1966, 51, 49-57.

Fobes, J. L., Ehrlich, A., \& Williams, K. Rear projection visual discrimination apparatus for prosimians. Laboratory Primate Newsletter, 1971, 10, 7-8.

Glickman, S. E., Clayton, K., Schiff, B., GuRitz, D., \& Messe, L. Discrimination learning in some primitive mammals. Journal of Genetic Psychology, 1965, 106, 325-335.

HASSLER, R. Comparative anatomy of the central visual systems in day- and night-active primates. In R. Hassler \& H. Stephan (Eds.), Evolution of the forebrain. Stuttgart: George Thieme Verlag, 1966.

Hodos, W. Evolutionary interpretation of neural and behavioral studies of living vertebrates. In F. O. Schmitt (Ed.), Neuro- 
sciences: Second study program. New York: Rockefeller University Press, 1970.

Hodos, W., \& Camprell, C. B. G. Scala naturae: Why there is no theory in comparative psychology. Psychological Review, 1969, 76, 337-350.

Horel, J. A., Schuck, J. R., \& MEYer, D. R. Effects of spatial stimulus arrangements upon discrimination learning by monkeys. Journal of Comparative and Physiological Psychology, $1961,54,546-547$.

Jolly, A. Prosimians' manipulation of simple object problems. Animal Behaviour, 1964, 12,560-570. (a)

Jolly, A. Choice of cue in prosimian learning. Animal Behaviour, 1964, 12, 571-577. (b)

KING, J. I., \& FoBEs, J. L. Hypothesis analysis of sameness-difference learning-set by capuchin monkeys. Learning and Motivation, 1975, 6, 101-113.

LEVINE, M. Hypothesis behavior. In A. M. Schrier, H. F. Harlow, \& F. Stollnitz (Eds.), Behavior of nonhuman primates (Vol. I). New York: Academic Press, 1965.

Masterton, B., \& SKeEN, L. C. Origins of anthropoid intelligence: Prefrontal system and delayed alternation in hedgehog, tree shrew, and bush baby. Journal of Comparative and Physiological Psychology, 1972, 81, 423-433.

ORDY, J. M., \& SAMORAJSKI, T. Visual acuity and ERG-CFF in relation to the morphologic organization of the retina among diurnal and nocturnal primates. Vision Research, 1968, 8, 1205-1225.

Rumbaugh, D. M. The learning and sensory capacities of the squirrel monkey in phylogenetic perspective. In L. A. Rosenblum, \& R. W. Cooper (Eds.), The squirrel monkey. New York: Academic Press, 1968.
Rumbaugh, D. M., \& ARnold, R. C. Learning: A comparative study of Lemur and Cercopithecus. Folia Primatologica, 1971, 14, 154-160.

Schuck, J. R. Pattern discrimination and visual sampling by the monkey. Journal of Comparative and Physiological Psychology, $1960,53,251-255$.

Schuck, J. R., Polidora, V. J., McConnell, D. G., \& Meyer, D. R. Response location as a factor in primate pattern discrimination. Journal of Comparative Psychology, 1961, 54, 543-545.

STEVENs, D. A. A comparison of learning in rhesus monkeys, cebus monkeys, and burmese cats. Unpublished doctoral dissertation, University of Oregon, 1965.

WARREN, J. M. The comparative psychology of learning. Annual Review of Psychology, 1965, 16, 95-118. (a)

WARREN, J. M. Primate learning in comparative perspective. In A. M. Schrier, H. F. Harlow, \& F. Stollnitz (Eds.), Behavior of nonhuman primates (Vol. I). New York: Academic Press, 1965. (b)

WARREN, J. M. Learning in vertebrates. In D. A. Dewsbury \& D. A. Rethlingshafer (Eds.), Comparative psychology: A modern survey. New York: McGraw-Hill, 1973.

WARREN, J. M., \& BARON, A. The formation of learning sets by cats. Joumal of Comparative and Physiological Psychology, 1956, 49, 227-231.

Zimmerman, R. R., \& ToRREY, C. C. Ontogeny of learning. In A. M. Schrier, H. F. Harlow, \& F. Stollnitz (Eds.), Behavior of nonhuman primates (Vol. I). New York: Academic Press, 1965.

(Received for publication January 19, 1976; accepted July $26,1976$. 